\title{
Invenciones de Caliban: cultura, humanismo y posoccidentalismo en Roberto Fernández Retamar
}

\author{
Inventions of Caliban: Culture, Humanism, and \\ Posoccidentalismo in Roberto Fernández Retamar
}

\section{Resumen}

Este trabajo analiza diferentes dimensiones críticas de la escritura de Roberto Fernández Retamar. La hipótesis que nos guía es que en los textos anticoloniales del poeta cubano se intuye una lectura heterogénea y no esencialista de la cultura latinoamericana, la cual se imbrica con una elaboración del concepto-metáfora de Caliban capaz de desorganizar las dicotomías culturales de la modernidad colonial. En la primera parte constatamos cómo la particularidad de su "Caliban" consiste en su capacidad de resistir a cualquier derivación cultural y escritural unilineal, logrando discurrir en sintonía con lo que Jacques Derrida define como la différance. Después reflexionamos sobre el humanismo tejido por Fernández Retamar con el mentado tropo: un humanismo anticolonial ideado desde una relación de agresividad entre lo "propio" y lo "ajeno". Finalmente analizamos el impacto de la noción de "posoccidentalismo" propuesta por el cubano en los principales resortes críticos del poscolonialismo latinoamericano. Concluimos cómo Caliban, en tanto símbolo, no es una autoridad de lo absoluto. Por el contrario, es una herramienta que busca deshacer los modos escriturales y epistemológicos ofrecidos por la cultura occidental, y que toma forma, dentro de la obra de Fernández Retamar, en un humanismo anticolonial y posoccidental aún en ciernes. 


\begin{abstract}
The goal of this research is to analyze the different critical dimensions of the writing of Roberto Fernández Retamar. We are guided by the hypothesis that in the anti-colonial texts of the Cuban poet, one intuits a heterogeneous and non-essentialist reading of the LatinAmerican culture, which is embedded with the elaboration of a metaphoric concept of Caliban, able to disorganize the cultural dichotomies of the colonial modernity. In the first part, we verified how the particularity of "Caliban" consists in his capacity of resisting any cultural derivation and unilateral writing, being related with what Jacques Derrida defines as différence. Secondly, we reflect on the humanism developed by Fernández Retamar with the well-known trope: the anticolonial humanism conceived from a relationship of aggressiveness between the "own" and the "other". Finally, we analyzed the impact of the notion "posoccidentalismo" suggested by the Cuban in his criticism of the Latin-American post colonialism. We agree with Caliban; a symbol is not an authority of the absolute. On the contrary, it is a tool that wants to undo scriptural and epistemic modes offered by the western culture, and that takes form, within the work of Fernández Retamar, in an anticolonial and post western humanism, which is still budding.
\end{abstract}

Keywords Caliban, humanism, différance, posoccidentalismo, culture.

\title{
Cultura y heterogeneidad en Caliban
}

En la escritura del poeta cubano Roberto Fernández Retamar (1930-2019) el ejercicio de idear un humanismo durante segunda mitad del siglo XX implica, fundamentalmente, un trabajo de indagación hermenéutica acerca del alcance histórico de los posibles tropos culturales que se desprenden de una historia horadada por las coordenadas coloniales de la modernidad. En este contexto que en 1971 presenta su célebre Caliban. Apuntes sobre la cultura de nuestra América como semilla de una lectura transcultural de Latinoamérica y el Caribe, pero también de una novedosa re-significación antillana del personaje del esclavo negro Caliban que aparece en la obra La tempestad de William Shakespeare. Con esto, el poeta logra sumarse al itinerario de pensadores que se habían apropiado anteriormente de esta pieza dramática -José Enrique Rodó en Ariel de 1900, George Lamming en Los placeres del exilio de 1960 y Aimé Césaire con su obra de teatro Una tempestad de 1969, por sólo nombrar algunos- para entender las claves de nuestra cultura. Este ensayo de Fernández Retamar es una de las reflexiones más reveladoras sobre un espacio estriado por modos inestables y contradictorios de 
pensar la cultura, el tiempo y la escritura, dando lugar, desde nuestro análisis, a una discontinuidad no sólo con las intervenciones críticas precedentes sobre la figura de Caliban; sino además con el posible anticolonialismo que se erige desde él.

En este sentido, al pensar la discontinuidad que consigue Fernández Retamar de un cierto campo crítico obsesionado por entender a la cultura latinoamericana desde una suerte de homogeneidad e identidad, pero también de los modos y las formas en que se modula un humanismo anticolonial a partir del reservorio político de lo letrado, lo que emerge es una reflexión como sede de aquello que Jacques Derrida (1997) define a la manera de una escritura anagramática al referirse a las relaciones diferenciales tejidas en una misma palabra en la que impactan otras significaciones opuestas a una voluntad metafísica. Más allá de cavilar el sentido y la perspectiva humanista de Caliban en el orden de los compromisos teóricos y temporales en los que tiene emergencia, lo interesante de pensarlo como parte de una escritura anagramática significa aceptar que el poeta cubano logra discurrir en un vocablo -"Caliban"- que resulta imposible de subsumir por completo en sólo una de sus variadas significaciones. Por eso, del mismo modo que Derrida piensa en La farmacia de Platón cómo pharmakon desafía la tentativa metafísica de la filosofía Occidental y también su principio de traductibilidad frente a la escritura, "Caliban" se resiste a toda derivación unilineal y a cualquier compromiso que pueda erosionar su ambivalencia y su heterogeneidad metafórica. De esta forma, develar la posibilidad de otras significaciones de Caliban no es otra cosa que engañar a la voluntad ontológica de la phoné -a la teoría esencialista del ser-presente dominada por la primacía del habla- que, siguiendo el derrotero derridiano, restringe la aparición transformadora de la différance.

Dicho esto, desde nuestra perspectiva, los fundamentos del tropo anticolonial calibánico de Fernández Retamar ya no se encuentran en aquello que refleja Caliban en relación a Ariel -el esclavo blanco de Prospero- a la manera de dos figuras que cristalizan modos distintitos de negociar con la cultura latinoamericana y caribeña, o en la estrategia de reforzar un compromiso antiimperialista que resultaría deudor de una lógica de la identidad. Ante la posibilidad 
de sortear un proceso de desmonte de las estabilidades culturales, el Caliban del poeta cubano se acerca mucho más a una lectura humanista transcultural de Latinoamérica y el Caribe que a un humanismo que descansa en las oposiciones binarias del pensamiento moderno colonial. Por ello, resulta elocuente cuando João Cezar de Castro Rocha en su estudio sobre Fernández Retamar señala que Caliban. Apuntes sobre la cultura de nuestra América, si bien hace reaparecer dentro del contexto político de la década del 70 la pregunta de si existe o no una cultura latinoamericana, posibilita, a su vez, una reafirmación autónoma de las culturas no hegemónicas haciando hincapié en el mestizaje -a la manera de un elemento central para responder la mentada interrogación sin seguir el camino idealizado de la intelligentzia europea- y donde su argumentación circula en razón de entender que el pasado colonial es un rasgo central del proceso histórico en el que aparece el vocablo. “O sea, tenemos que aceptar -agrega De Castro Rocha- la centralidad de lo ajeno en el núcleo mismo de lo que potencialmente somos -o podemos llegar a ser” (Roberto Fernández Retamar 107). Siguiendo esto, responder la pregunta “Existe una cultura latinoamericana?” no puede ignorar su trama histórica, pero tampoco puede ignorar las posibilidades de desmontar esa misma historia, pues la potencia epistemológica de Caliban -en términos de metáfora y vocablo- consiste en imaginar un porvenir en el que la cultura ya no sea pensada desde un conjunto de prácticas y discursos históricos que la vinculan a la fijeza y a la inmovilidad del espacio social, o, más peligrosamente aún, a la pureza identitaria. Si la noción de différance nos dice, señala Stuart Hall, cómo se "[p]one la palabra en movimiento hacia nuevos significados sin borrar la huella de sus otros significados" (Antiguas y nuevas 355), entonces "Caliban" consigue remover y alterar la economía de una cultura y una historia latinoamericana y caribeña pensada de manera sedentaria por el pensamiento occidental. Desde esta clave, Caliban, así, reposa en la movilidad, la heterogeneidad y la ambivalencia temporal y socio-histórica de la modernidad colonial.

Por esa razón, la lectura transcultural del Caliban de Fernández Retamar ya no puede ser equiparada con las intervenciones que le son precedentes sobre este 
mismo tropo. Mientras la presencia del significante "Caliban" era considerado por José Enrique Rodó como el antagonista del espíritu modernista y letrado de Ariel convirtiéndose este último en una de las figuras ilustradas del modernismo hispanoamericano- y para George Lamming representaba, en cambio, la posibilidad de una querella contra la autoridad intelectual inglesa, el cubano le transfiere un sentido donde la experiencia de la alteridad cultural sólo puede tener lugar a través de una circulación histórica en la que la metáfora del esclavo shakesperiano desorganiza la cadena de centramientos que estructuran al etnocentrismo de Occidente. No es otra cosa que el precedente de un humanismo anticolonial que opera como la antesala de una visión donde la cultura está siempre, dice Fernández Retamar, "en marcha":

Esa cultural, como toda cultural viva, y más en sus albores, está en marcha; esa cultura tiene, desde luego, rasgos propios, aunque haya nacido -al igual que toda cultura, y esta vez de modo espacialmente planetario- de una síntesis, y no se limita de ninguna manera a repetir los rasgos de los elementos que la compusieron. (Caliban 89)

Dicho esto, resulta interesante apreciar cómo años más tarde en su trabajo Pensamiento de nuestra América. Autorreflexiones y propuestas (1996) Fernández Retamar insiste en diseñar un recorrido histórico de los procesos independentistas de Latinoamérica y el Caribe, desde la Revolución haitiana dirigida por Toussaint L'Ouverture hasta la Revolución cubana de 1959, para pensar los sincretismos desde los que Caliban se va definiendo y redefiniendo en oposición a distintos campos del saber que normalizan y congelan una estrategia histórica que tiene su condición de posibilidad en la actualización del sentido anticolonial. Debido a ello, el cubano, de manera similar a como Hall piensa a las presencias fragmentadas, construidas y reconstruidas de la diáspora caribeña, entiende que en países continentales existen comunidades cuyas culturas, ya sea de modo superficial o no, se han fusionado con las aportadas por los colonizadores y conquistadores ibéricos, 
sumado a los aportes de africanos traídos como esclavos y de otros hombres y mujeres con otras procedencias (Caliban 357). Más allá de entender el entramado histórico de este asunto -que, por lo demás, ha sido tratado de manera sustanciosa en gran parte de la literatura caribeña antillana de mitad del siglo XX- lo que resulta fundamental en nuestra reflexión es la huella epistemológica de la lectura sobre Caliban de Fernández Retamar dentro de un humanismo anticolonial, y en lo que él mismo conceptualiza como una ideología posoccidental; cuestiones que impactan profundamente en los principales resortes de la teoría poscolonial latinoamericana.

\section{Humanismo y calibanismo}

Como adelantamos, Caliban. Apuntes sobre la cultura de nuestra América de Fernández Retamar pone en una situación de indisociabilidad y movilidad a los órdenes de lo histórico y de lo cultural como un ejercicio a contrapelo de los fundamentos occidentales. Esto resulta fundamental, pues, si bien el universo cultural en el que tiene emergencia el ensayo es el de una intelectualidad cubana puesta a prueba por los avatares del proceso socialista y los ataques del imperialismo internacional, el problema de la identidad del intelectual "nuestroamericano", al trazarse como uno de sus núcleos cardinales, nos habla de una escritura anticolonial que no se encuentra exenta de los procesos de subjetivación de los cuales forma parte (De Oto, Notas preliminares 267). Es en esta tensión entre un intento crítico de desorganizar las representaciones y las estabilizaciones identitarias no sólo instituidas por los estados-nación latinoamericanos, sino también de las ex metrópolis colonialistas, y un vocabulario emancipatorio que busca erigir una identidad del intelectual anticolonial, que Fernández Retamar se abre camino hacia el tejido mestizo e híbrido de la cultura latinoamericana y caribeña. Dice el escritor,

[E]xiste en el mundo colonial, en el planeta, un caso especial: una vasta zona para la cual el mestizaje no es el accidente, sino la esencia, la línea 
central: nosotros, 'nuestra América mestiza'. Martí, que tan admirablemente conocía el idioma, empleó este adjetivo preciso como señal distintiva de nuestra cultura, una cultura de descendientes de aborígenes, de africanos, de europeos -étnica y culturalmente hablando-. (Caliban 12)

Esto es, quizás, uno de los elementos más sobresalientes del anticolonialismo de Fernández Retamar al mostrar la manera en que sus afirmaciones más contundentes -aquellas, principalmente, dirigidas hacia la confección de otra historia del continente- no se cierran, ideando así un lugar de inestabilidad que impacta en la figura misma de Caliban. Esto lo acerca y distancia de una teoría sobre la liberación nacional que en los años 70 se había vuelto hegemónica. Desde ese lugar, el cubano se acerca a pensar al anticolonialismo como un movimiento - un ethos- que, nutriéndose de una larga genealogía de intelectuales latinoamericanos y caribeños, puede conducir a un proceso de liberación capaz de abrir las posibilidades dentro del continente para una resistencia antiimperialista. Bajo esta perspectiva, el colonialismo aparece como un fenómeno que en todo su espesor impide la construcción de estados-nación sin la tutela de un imperialismo cultural que se reactualiza en las más variadas formas.

Sin embargo, las variadas líneas que se bifurcan en el ensayo de Fernández Retamar, como apunta Carmen Centeno Añeses (2016), permiten su acercamiento desde una pluralidad de líneas de examen (Relecturas 65). Aquella observación resulta interesante para pensar la manera en que la presencia de Caliban, como metáfora y figura intelectual, hace que el escritor cubano se aparte de lo que se puede entender como una teoría binaria de las relaciones coloniales. De ahí que en su anticolonialismo se devela un ejercicio que rehúsa las posibles sobreterminaciones unilaterales de la relación colonizador/colonizado las cuales reproducen invertidamente el marco de representación maniqueo de la modernidad. Firmemente, se puede decir que si Caliban aparece dentro de esa larga genealogía de intelectuales que continúan la brega anticolonial mostrada por Fernández 
Retamar es como un "símbolo" que durante toda su existencia ha pasado sobre la historia el bisturí del sincretismo. Para expresar el potencial epistemológico de esta idea, el poeta entiende que el conflicto irresoluble que acaece en el mundo poscolonial es el de la disputa por la lengua disponible -o sea, la lengua del colonizador-, la cual, por momentos, es habitada, subvertida y resignificada por Caliban, como cuando utiliza el idioma que Próspero le enseñó para maldecirlo, "para desear que caiga sobre él la 'roja plaga'” (Caliban 52).

La operación calibanesca, en consecuencia, se puede resumir como un profundo rechazo a la hegemonía cultural colonizadora de la lengua, en un espacio que es definido con precisión por Mary Louise Pratt (2010) como una "zona de contacto" en la que, por lo general, acaecen relaciones de poder asimétricas. Si volvemos un poco a la idea de entender al vocablo Caliban desde la différance derridiana, lo que aparece, por lo tanto, es un tropo que sugiere la posibilidad de socavar los efectos estabilizadores del pensamiento moderno por medio de la deglución de prácticas discursivas y simbólicas propias de la geocultura colonizadora, con el horizonte de impugnar el sentido original de las mismas y subvertir sus efectos desmovilizadores. Fernández Retamar en su texto Caliban ante la Antropofagia explica en parte esta idea al apuntar cómo tanto la Antropofagia del modernismo brasileño de los años 20 como su Caliban se proponen en un sentido anticolonial reivindicar y esgrimir símbolos válidos que, si bien habían sido desautorizados por la historia oficial, en el mundo poscolonial son fecundamente útiles para pensar la forma de reclamar el derecho de incorporarnos al mundo, "de acuerdo con características que nos son propias" (Caliban 148); para de esa manera objetar, sea de paso, el presunto carácter bestial con el que el humanismo europeo ha definido al esclavo deforme del drama shakesperiano.

Sacudir el polvo de esa indiferenciación con la que el pensamiento occidental ha clasificado a Caliban nos habla, así, de cómo aquella figura, no sólo desestructura los limites simbólicos del imaginario colonial; sino también, siguiendo a Fabienne Viala (2016), da lugar a un "canibalismo cultural" propiamente caribeño; cuestión que no es otra cosa que la exégesis de un 
apoderamiento "de los métodos filosóficos de las bibliotecas de los antiguos amos coloniales para demostrarles que su hegemonía civilizadora ha caducado a mediados del siglo XX" (Tragedia, filosofía y cultura 292).

Estas cuestiones nos llevan a pensar sobre cuáles son los nudos críticos dentro de la escritura de Fernández Retamar desde los que se puede desprender la idea de un humanismo anticolonial. A partir de lo mencionado hasta el momento, podemos apuntar $\mathrm{r}$ que uno de los móviles principales del cubano en Caliban. Apuntes sobre la cultura de nuestra América es idear un esquema semántico que permitiese utilizar estratégicamente "una genealogía heroica de la que el autor también de siente parte" (Centeno Añeses, Relecturas 65). Esta estrategia, sin embargo, no ignora, por una parte, que el proceso descolonizador es un problema en ciernes -inconcluso-, pues la existencia de lo que años posteriores distintos autores de las humanidades y las ciencias sociales latinoamericanas definirán como "colonialidad" -a la manera del reverso cultural de la modernidad- implica una enunciación severa que necesita enraizarse en una temporalidad contradictoria que no sigue el curso temporal violento y lineal instituido por la noción civilizatoria del Occidente europeo y, por otra parte, que, si bien las diferencias entre una cultura colonizada y una colonizadora siguen siendo profundas, reinterpretar a Caliban a la luz de la sociedad poscolonial involucra también una reinterpretación del vínculo entre ambas culturas desde lo que Hall entiende como una "doble inscripción". Esta "doble inscripción", dice Hall, consigue descomponer "los espacios claramente demarcados de 'adentro'/'afuera' del sistema colonial de los que las historias del imperialismo se han beneficiado durante tanto tiempo, es precisamente la que el concepto de lo 'postcolonial' ha resaltado" (¿Cuándo fue lo "postcolonial? 568).

Se puede pensar que la respuesta a la pregunta con la que abre el ensayo de si existe o no una cultura latinoamericana desencadena a lo largo de la escritura de Fernández Retamar una noción de humanidad que toma forma en un proceso argumental guiado por sostener cierto ideario anticolonial de José Martí -como se logra constatar en el acápite Otra vez Martí-, pero también por rediseñar estratégicamente una figura-la de Caliban- donde el ser humano deviene en parcela 
de una heterogeneidad que afirma lo "propio" frente a lo "ajeno". "Nuestro símbolo no es pues Ariel, como pensó Rodó, sino Calibán. Esto es algo que vemos con particular nitidez los mestizos que habitamos estas mismas islas donde vivió Calibán" dice el poeta cubano en el apartado Nuestro símbolo, para más adelante agregar que "[n] o conozco otra metáfora más acertada de nuestra situación cultural" (Caliban 49). Estas características de Caliban, de hecho, visibles a lo largo del escrito, muestran el impacto del locus de enunciación del intelectual latinoamericano, el cual, en el caso particular de Fernández Retamar, consigue exhibir aquello que De Castro Rocha define como una situación existencial periférica en la que permanentemente impacta la necesidad de crear algo nuevo, de vislumbrar la posibilidad de erigir una oscilación constante entre lo "propio" y lo “ajeno" en vistas de interrumpir las certezas culturales impuestas por la cultura europea occidental. Certezas, a su vez, que históricamente han fundado un sentido de humanidad que omite la heterogeneidad constituyente del continente (Roberto Fernández Retamar 113).

No resulta menor que en los mismos años del Caliban de Fernández Retamar el escritor brasileño Silviano Santiago (2018) en su El entre-lugar del discurso latinoamericano apunta que la mayor contribución de Latinoamérica a la cultura occidental sea la destrucción de los conceptos de unidad y pureza, como una manera crítica de desviar la norma; de, principalmente, resignificar los elementos preestablecidos $\mathrm{y}$, supuestamente, inmutables que los europeos exportaban al llamado "nuevo mundo" (El entre-lugar 70). El Caliban del cubano puede ser asociado con la observación de Santiago sobre el carácter agresivo de la cultura continental, en tanto figura que cristaliza una dialéctica no asuntiva que da lugar a una geografía y una radiografía cultural de la "asimilación y la agresividad, de aprendizaje y de reacción, de falsa obediencia" (70). El calibanismo de la lengua, de esta forma, es un paso necesario -por no decir el principal- para una interrogación reflexiva sobre la agresión de los modelos culturales "originales" y que en Fernández Retamar se verifica cuando anuncia que "nuestro símbolo" es un Caliban que, a diferencia del Ariel de José Enrique Rodó, pone en escena un ritual 
antropofágico capaz de organizar un juego con los signos dominante. Se aprende, así, otra mirada cuestionando los espacios delimitados por la mirada de las epistemologías imperiales. Una estrategia desde la que se traza un humanismo labrado desde lo heterogéneo -a partir de la différance- que convierte al ejercicio de la escritura anticolonial en una cuestión mucho más compleja.

De este modo, lo que resulta notable de esta definición de lo culturalmente heterogéneo es que insinúa la posibilidad de asediar el concepto de "ser humano" fundado por la modernidad europea, en tanto que la escritura anticolonial asuma la condición calibanesca de Latinoamérica y el Caribe. La relación de disociación cultural entre "centros" y "periferias", entre "mismidad" y "otredad", instituida durante los procesos de conquista por el pensamiento moderno occidental, $\mathrm{y}$, en parte, reproducida de forma invertida por las teorías del "ser" que tuvieron su emergencia dentro del espacio latinoamericano, alerta sobre la necesidad de inventar, al igual como Fernández Retamar imagina un "símbolo", un humanismo mediante "un conflicto creativo con lo ajeno" (De Castro Rocha, Roberto Fernández Retamar 124). Aquello se encuentra lejos de entender que la fuerza motriz de ese humanismo es una posible y estimulante hibridación cultural que finalmente deteriore el conflicto histórico que se desprende desde nuestra relación con lo "ajeno", sino, muy por el contrario, se trata de un humanismo, tal y como lo ensaya Fernández Retamar, que busca operar bajo otros marcos epistemológicos, como un intento de trasgredir la mirada binaria colonial sobre lo "propio" y a la manera de una perspectiva crítica capaz de conservar, al decir de Eduardo Grüner (2011), "el carácter de tensión y conflicto trágico que tuvo ese 'choque de culturas' del que surgió - con su indudable riqueza, pero asimismo con sus deformaciones producto de la explotación- la llamada 'cultura afro-latina'" (Ausencias posibles 277). El aspecto al que hace referencia Grüner resulta decisivo para entender el humanismo de Fernández Retamar, pues, como hemos visto, su ensayo al partir con la pregunta de si existe una cultura latinoamericana sugiere cómo en el orden de la cultura poscolonial aún subyacen las asimetrías del poder colonial instaladas desde la conquista; lo que, sin duda, nos habla de esa tensión irresoluble con lo "ajeno". 
Por tanto, el humanismo que se sugiere en la escritura del cubano es, en buena parte, expresión de una reflexión sobre el carácter transcultural latinoamericano y caribeño que resulta imposible disociarlo de su condición de colonialidad; entendiendo esta última como una situación originaria de esa historia moderna reformulada críticamente y desde otra mirada en Caliban. Apuntes sobre la cultura de nuestra América.

La importancia de este último tema que involucra fuertemente al humanismo fundado por la modernidad europea ha sido destacado por MichelRolph Trouillot (2017) cuando nota que una de las operaciones más perniciosas y racistas de la colonización imperial europea es cómo mientras se perfeccionan los procesos conquista y de compra de hombres y mujeres, más escriben y hablan del hombre los filósofos europeos. Esto da lugar a reflexiones que, atendiendo a la supuesta naturaleza ontológica y ética de los pueblos colonizados, en última instancia asumen que algunos humanos lo son más que otros. De esta forma que en el horizonte de Occidente a fines del siglo XVIII “el Hombre (con H mayúscula) era principalmente europeo y masculino" (Silenciando el pasado 63). Trouillot, a su vez, muestra cómo la instalación de esta nomenclatura, donde la humanidad de los sujetos es definida por connotaciones positivas o negativas vinculadas al color de piel, corre de manera paralela a la trasformación del etnocentrismo europeo en racismo científico. Así, el concepto ilustrado de "hombre" ocurre en un contexto de prácticas de dominación colonial y de acumulación del capital capaces de configurar una visión racista del progreso histórico, cultural y económico que resulta crucial para darle forma a una perspectiva donde los hombres son perfeccionables, y también, al menos teóricamente, los subhumanos. "La perfectibilidad se convirtió en un argumento en el debate práctico: el otro occidentalizado fue cada vez más visto como más rentable por Occidente, especialmente si podía convertirse en un trabajador libre” (67). La oposición "Hombre blanco" - "Nativo negro", entonces, comienza a teñir el ideario de humanidad ilustrado, y es gracias a la instrumentalización colonial que se instala como posibilidad histórica. En efecto, el sentimiento humano del hombre europeo 
es autojustificado a partir de las diferencias que cultiva con el hombre negro; proceso que no es otra cosa que la puesta en práctica de un principio donde el sujeto racista "ve su propia humanidad no en aquello que lo une a los otros, sino en lo que lo distingue" (Mbembe, Crítica 81).

La incidencia de los discursos anticoloniales dentro de lo que se puede entender como una crítica ampliada a las vetas racistas del humanismo europeo demuestra la forma en que parte importante del pensamiento contemporáneo del Caribe empieza a reflexionar sobre lo que posteriormente el peruano Aníbal Quijano (2007) entenderá a fines de la década de los años 80 como la "colonialidad del poder". Bajo la perspectiva de Quijano, la "colonialidad del poder" configura una red jerárquica, racista y eurocéntrica de identidades sociales donde las poblaciones del mundo se dividen entre "inferiores y superiores, irracionales y racionales, primitivos y civilizados, tradicionales y modernos" (Colonialidad del poder 95). Esta perspectiva propuesta por el sociólogo peruano resulta significativa, no sólo para, como en parte ya hemos advertido, advertir el carácter constitutivo que tienen las experiencias coloniales locales en relación a la red global de poder dibujada por la modernidad; sino también para mostrar la manera en que la colonización siempre estuvo cruzada por vinculamientos transculturales orquestados bajo las relaciones de saber/poder.

A su vez, son autores como Aimé Césaire y Frantz Fanon, entre otros, los que movilizan años anteriores a las elaboraciones de Quijano, específicamente en la segunda mitad del siglo XX, una fecunda reflexión crítica donde el humanismo europeo aparece como un pilar ideológico indisociable del racismo moderno y, por lo mismo, de la colonialidad. Los temas que organizan el derrotero teórico y cultural del pensamiento anticolonial de ambos teóricos al dialogar, al igual que Fernández Retamar, con la filosofía europea -principalmente con la dialéctica hegelianamarxista, en el caso de Césaire, y con la fenomenología francesa por parte de Fanon- consiguen mostrar cómo la genealogía caribeña del humanismo anticolonial ha de considerar siempre la presencia constitutiva de lo "ajeno"; tomando a éste último como un elemento a resignificar, desorganizar, impugnar, aprender y 
desaprender, mediante un tarea hermenéutica en la que su horizonte es contribuir al nacimiento de un humanismo, al decir de Fernández Retamar siguiendo al poeta Nicolás Guillén, que dé lugar a un "perfil definitivo del hombre".

Bajo lo anterior que es en el trabajo de 1976 titulado Para el perfil definitivo del hombre donde Fernández Retamar pasa revista sobre la posibilidad certera de un nuevo humanismo emergido desde la periferia y pivoteado por el declive del humanismo occidental. Es el modernismo hispanoamericano, la antropofagia brasileña, el negrismo antillano, el anticolonialismo caribeño, el indigenismo peruano, etc., los que, en una dialéctica irresoluble, devoran los valores europeos “para expresar los nuestros" (Para el perfil 529). El calibanismo de reclamar el derecho a estar en el mundo se va constituyendo en esos pequeños fragmentos de la historia latinoamericana, los cuales configuran una tradición local que a los ojos de Fernández Retamar dan el puntapie inicial para un diálogo al mismo nivel que el de la filosofía europea y hacia un humanismo capaz de ensanchar su horizonte crítico lejos de cualquier parroquialismo estéril. Mientras esto ocurre, la perspectiva culturalmente heterogénea abierta por Caliban da cuenta de que el hombre, dice el cubano, "es también mujer, negro, amarillo, mestizo, obrero y campesino, asiático, latinoamericano y africano" (538). Este humanismo en cuestión viene a demostrar la complejidad de una cultura en la que el intercambio acontece como condición del conflicto y como deterioro de la lógica provincialista instalada por la tradición europea occidental.

\section{Posoccidentalismo y pensamiento anticolonial}

A partir de lo mencionado hasta el momento, podemos decir que uno de los propósitos del autor de Caliban. Apuntes sobre la cultura de nuestra América al momento de pensar una redefinición de la cultura latinoamericana desde una crítica a los valores y los imaginarios euroccidentales es confirmar la posibilidad de una mirada no hegemónica, desde un paradigma que se vuelve enormemente fecundo dentro de la literatura anticolonial del siglo XX. Sin embargo, la actualidad de este ejercicio escritural construido desde el concepto de Caliban, pensamos, no se debe 
exclusivamente a su vasta inclusión dentro de los diversos itinerarios sobre la filosofía, la cultura y la literatura de nuestra región, sino, principalmente, porque desde él se desprende una intelectualidad que se piensa y se crea en una denuncia a las investiduras coloniales que aún horadan el suelo desde el que se enuncia. A raíz de esto, vemos necesario destacar que el escenario de lo que se puede definir como una teoría crítica de la cultura latinoamericana no ha quedado incólume de la influencia de Fernández Retamar, más aún cuando es posible constatar cómo su Caliban sigue siendo una caldera de elementos críticos para pensar nuestros vínculos, nuestras apropiaciones y nuestras estrategias de análisis literarios en una cultura desde la que incesantemente sobresale el drama colonial shakesperiano, pero más aún, la tempestad de una colonialidad que se funde vehementemente con la modernidad y el imperialismo occidental. Desde ahí que la idea de cavilar la configuración de lo "propio" resulta indisociable, no sólo de la pregunta sobre si autorizar o no la presencia de un discurso metropolitano, sino también de la posibilidad de desviar todo molde cultural que se empecine en instalar un modelo único de conocimiento, que no es otra cosa que levantar, al decir de Florencia Bonfiglio (2016), una carnavalización de los modelos y de los sentidos impropios que subraye el afán descolonizador de Caliban (Calibán o los placeres 159). Esto se vincula con la idea de la différance que hemos expuesto a lo largo del presente trabajo, en tanto movimiento de resistencia lingüística de la cultura, en tanto postulación de una diferencia que no se deja apropiar por ninguna autoridad del habla, pues de lo que se trata para Fernández Retamar es de acentuar la agresividad calibánica de lo enunciado en la clave de una política anticolonial.

Ahora bien, atendiendo a la influencia de los desarrollos del poeta cubano dentro de la teoría crítica de la cultura latinoamericana, resulta importante atender al impacto que tiene en la teoría poscolonial del semiólogo argentino Walter Mignolo su concepto de posoccidentalismo. Nuestra américa y Occidente es el trabajo de Fernández Retamar de 1976 donde aparece brevemente el concepto de posoccidentalismo para definir una categoría desde la cual superar y sobrepasar a la ideología capitalista occidental, y deshacer, sea de paso, las categorías 
geoculturales "Occidente" y "Oriente" que resultan cardinales para el pensamiento moderno, su política y su poder. Siguiendo los problemas que el cubano encara en Caliban. Apuntes sobre la cultura de nuestra América, el posoccidentalismo aparece posteriormente como una propuesta epistemológica que, a partir de una recusación del capitalismo imperialista, intenta darle hondura al locus de enunciación fronterizo de una intelectualidad latinoamericana y caribeña que descentra la noción de Occidente y que se desplaza hacia otras zonas y regiones culturales en un esfuerzo de hablar y pensar, desde cierta especificidad, la historia de los legados coloniales. Desde el punto de vista de Fernández Retamar (2016), aquella perspectiva tiene su punto de inflexión, por ejemplo, dentro del materialismo histórico desarrollado por figuras heráldicas, como José Carlos Mariátegui, Julio Antonio Mella y Rubén Martínez Villena (Nuestra América y Occidente 256), pero es ante la crisis del capitalismo occidental que el posoccidentalismo viene a prolongar el ideario anticolonial en el campo de la crítica cultural -en tanto que discute y desarticula los ecos coloniales de nuestra modernidad- del espacio latinoamericano y caribeño; comprendiendo a este último como un lugar idóneo para la elaborar y abrir un debate sobre una perspectiva periférica que busque desactivar los disciplinamientos epistemológicos y las categorías del saber organizadas por Occidente.

Como es reflexionado por Fernández Retamar, el problema de la perspectiva posoccidental, en consecuencia, parte de preguntas como ¿qué es Occidente? ¿qué es ser occidental? y ¿a qué espacio geocultural se hace mención cuando se habla de mundo occidental?, entre otras. De esta forma, en Nuestra américa y Occidente el cubano empieza visualizando un problema fundamental referido a la necesidad de ver cómo dentro del pensamiento latinoamericano se ha abordado la definición de "Occidente" o de "mundo occidental", cuestión, sin duda, que lo conduce a un relevamiento crítico de tales conceptos cuando, como apunta ahí, se abre paso "entre la maleza” (228). “Occidente”, observa el cubano, siempre se ha asociado con las bases geográficas europeas. Sin embargo, el contenido moderno del término es otro, pues conceptos como "occidentalistas" asociados a la 
idea de una "humanidad europea" entran en desuso en el siglo XX cuando "Occidente" empieza a relacionarse más que nada con la historia del capitalismo europeo, convirtiéndose así en un constructo predilecto durante la Guerra Fría. Siguiendo a Fernández Retamar, es a mediados del siglo XX en Latinoamérica donde pensadores como Leopoldo Zea y José Carlos Mariátegui empiezan a asociar a Occidente con los ideales culturales, materiales y políticos de la modernidad europea. "Sociedad occidental" para Mariátegui, por ejemplo, es sinónimo de sociedad capitalista, mientras para Zea hace referencia a los pueblos de Europa y Estados Unidos que han realizado el proyecto moderno, con todas las consecuencias que ha traído esto.

Bajo lo anterior, surge la siguiente pregunta: ¿cuál es el peso de estas ideas expuestas por latinoamericanos sobre las relaciones entre América y Occidente? Las fuentes del pensamiento latinoamericano relevadas por el poeta cubano dan lugar a una teorización desde la que, no sólo se advierte la originalidad de la mirada periférica - un poco como lo manifiesta con su Caliban- sino también, se reformula la manera en cómo se ha pensado nuestra relación con la modernidad capitalista, principalmente sobre nuestro lugar en eso que se ha llamado "Occidente" y acerca de cómo su formación conceptual eurocéntrica ha necesitado de la elaboración de espacios geohistóricos colonialmente diferenciados en los que Latinoamérica y el Caribe cumplen un lugar fundamental, a la manera del área cultural en la que se ha instituido de la manera más brutal el capitalismo imperial de la colonialidad. De ahí que Fernández Retamar propone indagar en las verdaderas raíces de la asignación histórica de nuestro continente dentro de Occidente, dando cuenta, por un lado, de la indisociabilidad que acaece entre la emergencia del capitalismo occidental y la colonización de América, y, por otra parte, de cómo las guerras de independencias del continente, inauguradas por la Revolución Haitiana de finales del siglo XVIII y principios del XIX, revelan una contradicción entre las ideas de Occidente en el suelo latinoamericano y la praxis de ese mismo Occidente.

Lo que el cubano intenta problematizar es la dimensión cultural-espacial de Occidente, aquello que años después en el trabajo de Fernando Coronil (1999) se 
entenderá como una "representación" en la que el despliegue del poder de la Europa tiene el privilegio global de construir jerarquías fuertemente instituidas en taxonomías desde las que se sigue pensando de manera binaria. "Como resultados de estos cambios -dice el antropólogo venezolano-, las categorías espaciales que nos son familiares están siendo desarraigadas de sus sitios originales y adosadas a nuevos lugares" (Más allá del occidentalismo 142). Coronil pone el acento en lo que encarna Occidente en el terreno del desarrollo capitalista: progreso moderno, universalización y expansión del capital. Dado esto, el "Occidentalismo" se devela como una epistemología imperial que vincula, siguiendo al antropólogo, "la producción de representaciones occidentales de alteridad con las construcciones implícitas de la individualidad que las sustentan" (Coronil, Occidentalism 319). Un ejemplo de tal operación es la manera en que la modernidad narra a las historias locales en los términos de una supuesta historia universal y de un trayecto teleológico que tiene su culminación en el Occidente europeo. En ello, se oscurece la participación de las sociedades no europeas en la creación del mundo moderno, dando lugar a un sistema de clasificación en el que el capitalismo es el principio organizador de las diferencias culturales; lo que estimula, sin duda, el continuo desarrollo de un progreso histórico e ideológico a costa de, y no con, las áreas culturales que han sido pensadas como las "periferias" del "centro". De esta forma, un aspecto importante del posoccidentalismo de Fernández Retamar, destaca Coronil, es la conformación de una categoría crítica que se propone superar los profundos legados de la condición colonial instituida por el "Occidentalismo" en Latinoamérica, que en sus propias elaboraciones se traduce como un "Más allá de occidente" (beyond Occidentalism 319).

Esto último que apunta Coronil es la base de la novedad epistemológica del concepto propuesto por el poeta cubano, el cual navega de la mano de ese sentido anticolonial que años antes le había asignado a la figura de Caliban. Proclamar una relación de agresividad y de contacto con Occidente -en la cual se ven involucrados los órdenes de la lengua y la cultura- da lugar, entonces, a un compromiso con el extenso itinerario de los conocimientos silenciados por las narraciones modernas, 
pero también con la necesidad de superar fecundamente aquellos patrones conceptuales que se han visto coludidos con una práctica colonial en la que el proceso de occidentalización de Latinoamérica y el Caribe vienen a ser el mecanismo por excelencia desde el cual se piensa nuestra relación con el mundo. De ahí que, como bien apunta Mignolo (2002), Fernández Retamar consigue idear una palabra-clave que aparece como la consecuencia lógica de su revisión del pensamiento en América Latina dese el siglo XIX (Posoccidentalismo 847). En palabras del poeta cubano:

Este pensamiento solo podía brotar en el seno de aquel mundo, que en su desarrollo generó a su sepulturero, el proletariado, y su consiguiente ideología: pero esta no es ya una ideología occidental, sino en todo caso posoccidental: por ellos hace posible la plena comprensión, la plena superación de Occidente, y en consecuencia dota al mundo no occidental de un instrumento idóneo para entender cabalmente su difícil realidad y sobrepasarla. (Nuestra América y Occidente 256)

En la propuesta poscolonial de Mignolo, la idea de posoccidentalismo de Fernández Retamar habla de la eventualidad de un nuevo espacio de reflexión subalterna capaz de redefinir los fundamentos teóricos de las fronteras orientandos en clave descolonizadora sus sensibilidades epistemológicas. A su vez, lo característico del posoccidentalismo, por un lado, es que viene de definir para Mignolo cierta sensibilidad poscolonial en el marco de un locus de enunciación específicamente latinoamericano y caribeño. No consiste una suerte de relevamiento situado de la crítica poscolonial de Homi Bhabha, Gayatri Spivak y Edward Said, sino en una estrategia crítica que temporalmente es anterior al poscolonialismo, pues se configura desde los diferentes discursos de nuestra región que han pensado los legados coloniales instituidos tanto por la modernidad como por su ideología occidentalizadora. Por otro lado, dentro de la trama de esos discursos posoccidentales, acertadamente el semiólogo argentino ve la emergencia 
de una razón subalterna nutrida de la práctica teórica impulsada por los movimientos de descolonización tras la Segunda Guerra Mundial. Transgredir el concepto moderno de razón enquistado en el discurso del imperialismo occidental vendrá de la mano, así, de la rearticulación de las largas historias de subalternización, las cuales, rearticuladas en un pensamiento fronterizo, consiguen trasgredir las herencias coloniales y subvertir la división dicotómica entre "civilizados" y "barbaros", "modernos" y "premodernos", en las que se consolidaron las reglas y los órdenes discursivos del "Occidentalismo". A nuestro entender, en el razonamiento de Mignolo autores como Aimé Césaire, Frantz Fanon y Raphaël Confiant, entre otros, cristalizan la idea de Fernández Retmar de un discurso posoccidental en tanto que trazan una epistemología, como Caliban, del contacto, de la agresividad y del intercambio conflictivo entre lo "propio" y lo “ajeno" - o sea, una frontera epistemológica- que desvía las categorías modernas y consigue trascenderlas en la integración de lo que ellas mismas negaron. Así, por ejemplo, en la medida en que "civilización” sirvió como una categoría que negó el poder de conocimiento de la "barbarie", apunta Mignolo,

la incorporación de la barbarie en los términos negados por la civilización, es lo que permite trascenderla no reivindicando su opuesto (la barbarie) sino reivindicando la fuerza de la frontera que crea la posibilidad de la barbarie de negarse a sí misma como barbarie-en-la-otredad; de revelar las barbarie-en-la-mismidad que la categoría de civilización ocultó; y de generar un nuevo espacio de reflexión que mantiene y trasciende el concepto moderno de razón. (Posoccidentalismo 856)

De lo anterior, podemos afirmar, en rasgos generales, que la crítica poscolonial Mignolo se orienta en función de una estrategia tendiente a deconstruir las divisiones geoculturales y geopolíticas del pensamiento colonial moderno, y donde el poscolonialismo tradicional es interrogado en sus insuficiencias, cuando se trata de pensar nuestros problemas, ya que es infrecuente encontrar en los 
fundamentos de éste el reconocimiento de la dimensión colonial de la historia latinoamericana y la relación constituyente entre la modernidad y la colonialidad el poder (Mignolo, Historias locales 288). La cuestión de la geopolítica del conocimiento, entonces, es fundamental para el semiólogo al momento de rastrear posibles discursos posoccidentales críticos a la universalidad de las tradiciones epistemológicas de la modernidad, pues intenta explorar -al igual como lo hace Fernández Retamar con su revisión del pensamiento latinoamericano- discursos que, al cuestionar las consecuencias del largo proceso de occidentalización, de expansión colonial y de globalización que se abre desde 1492 en las Américas, encuentran su lugar de enunciación y de práctica oposicional dentro de Latinoamérica y el Caribe.

En esta línea que el semiólogo destaca que uno de los grandes aportes de Fernández Retamar es haber mostrado cómo el occidentalismo es una palabra clave en la historia latinoamericana que, a diferencia del orientalismo, fue creado desde sus comienzos como la extensión de Europa y no como su alteridad (174). "La travesía del colonialismo y del capitalismo en América Latina -agrega Mignolopermite a Fernández Retamar proponer al postoccidentalismo como una categoría marxista, si bien incorporada a la historia colonial de la explotación amerindia y del tráfico de esclavos africanos" (174). De ahí que el posoccidentalismo se revela como un resorte crítico que es retomado por Mignolo para mostrar la existencia de discursos, teorías e intelectuales que perforan la distribución geohistórica del conocimiento instituida por la colonialidad. Desde una teorización subalterna, esta crítica, entonces, va tomando forma como una orientación contramoderna en respuesta a los diferentes tipos de legados coloniales que comparten el proceso de expansión occidental identificado, desde Latinoamérica y el Caribe, como modernidad/colonialidad. Con la agudización del proceso de globalización y la transnacionalización de las cultural locales-periféricas, el pensamiento sobre el "mestizaje" de Gloria Anzaldúa, la idea de "entre-lugar" de Silviano Santiago y la noción de "canibalismo" de Haroldo de Campos, son, según Mignolo (1995), nuevas formas de esta crítica posoccidental que intenta cavilar más allá de las 
dicotomías producidas por el occidentalismo. Lo que Mignolo intenta advertir es que se trata, fundamentalmente, de una estrategia que desde las reflexiones de Fernández Retamar da lugar a lo que se puede llamar un Tercer Mirado configurado por diferentes legados coloniales para el conocimiento y el conjunto de la civilización planetaria (Posoccidentalismo 856). En definitiva, consiste en poner a América Latina y el Caribe en la nueva escena global desde una contra-lectura que sustituye los discursos de la misión civilizatoria y sus "fronteras de la civilización”, poniendo ahora a las fronteras como un espacio en el que surge una nueva conciencia descolonizadora.

A lo largo de este trabajo hemos transitado por diversos elementos del derrotero teórico de Fernández Retamar, advirtiendo sus avatares en el marco de los flujos y reflujos propios de la cultura latinoamericana y caribeña. En cierto sentido, la crítica cultural desarrollada por el poeta cubano es, al igual que parte de la teorización anticolonial de mitad del siglo XX, un tipo de discurso que se inscribe en una práctica teórica y política en la que resulta determinante su ubicación geohistórica. La rigidez de los sentidos labrada y defendida por el pensamiento moderno occidental se ve infringido, entonces, por un arco amplio de reflexiones inscritas en la sensibilidad del lugar desde el que se enuncia y en una emergencia política que buscaba enfrentar los avatares del capitalismo imperialista. Empero, la escritura de Fernández Retamar, al igual que otros teóricos del Caribe, labra un pensamiento que no agota sus posibilidades epistemológicas en el marco de esas urgencias históricas. De ahí que, como bien muestra Edward Said (2004), resulta interesante y fecundo pensar una posible desarticulación de las fronteras textuales, como descomponer los actores depositados en la escritura para así redefinir nuestros tradicionales modos de comprenden tanto a la cultura como al texto. Así, el Caliban de Fernández Retamar pensado, en parte como lo hemos intentado en el presente escrito, desde la différance nos alerta de una figura desde la que se advierte un no retorno al origen, una castración figurativa, siguiendo a Said, que trastorna perpetuamente los cimientos culturales a los que nos hemos visto acostumbrados, y que, en gran medida, son desarticulados por la heterodoxa textualidad abierta por 
el poeta cubano. Huir de una clasificación definitiva es tomar la ruta calibanesca como una estrategia que inaugura nuevos modos y nuevos sentidos de entender el anticolonialismo, donde lo importante ya no es la síntesis, sino colocar al desnudo las fuerzas enfrentadas que toman lugar en esa compleja relación que acaece entre lo "propio" y lo "ajeno" en la cual se hace imperiosa la puesta en cuestión de los mandatos metafísicos del pensamiento moderno. Fernández Retamar sugiere, por todos los medios, que Caliban, en tanto símbolo, no es una autoridad de lo absoluto. Por el contrario, es una herramienta que busca deshacer los modos culturales ofrecidos por la cultura occidental, y que toma forma en un humanismo anticolonial aún en ciernes. Un pensamiento posoccidental audaz que busca superar el poder discursivo y ontológico del colonialismo, y que resulta fundamental dentro de cierto itinerario poscolonial que se ha asomado en parte de nuestras humanidades.

\section{Bibliografía}

Bonfiglio, Florencia. "Calibán o los placeres de la apropiación: comienzos caribeños de La tempestad'. Vidas de Caliban. Herencia y porvenir del calibanismo. Julio César Guanche - compilador. La Habana: Editorial José Martí. 151-207.

Castro Rocha, João Cezar de. "Roberto Fernández Retamar: autor-matriz de "Nuestra América". Vidas de Caliban. Herencia y porvenir del calibanismo. Julio César Guanche - compilador. La Habana: Editorial José Martí. 91-126.

Centeno Añeses, Carmen. "Relecturas de Calibán". Vidas de Caliban. Herencia y porvenir del calibanismo. Julio César Guanche - compilador. La Habana: Editorial José Martí. 52-58.

Coronil, Fernando. "Más allá del occidentalismo: hacia categorías geohistóricas no-imperialistas", Teorías sin disciplina (latinoamericanismo, 
poscolonialidad y globalización en debate). Santiago Castro-Gómez y Eduardo Mendieta - editores. México: Miguel Ángel Porrúa, 1998. 121146.

. "Occidentalism". The Fernando Cornil Reader: The struggle for life is the matter. Durham: Duke University Press, 2019. 315-322.

De Oto, Alejandro. "Notas preliminares sobre el archivo en contextos poscoloniales de investigación". Genealogías críticas de la colonialidad en América Latina, África, Oriente. Karina Bidaseca - coordinadora. Buenos Aires: CLACSO, 2016. 263-274.

Derrida, Jacques. La diseminación. Madrid: Espiral / Ensayo, 1997.

Fernández Retamar, Roberto. "Caliban ante la antropofagia". Todo Caliban. Buenos Aires: CLACSO, 2004.

. Caliban. Apuntes sobe la cultura de nuestra América. Buenos Aires: Editorial la pléyade, 1973.

. Caliban y otros ensayos. Holguín: Ediciones Holguín, 2016.

. "Nuestra América y Occidente". Pensamiento anticolonial de nuestra América. Buenos Aires: CLACSO, 2016. 227-264.

. Para el perfil definitivo del hombre. La Habana: Editorial Letras Cubanas, 1985.

. "Pensamiento de nuestra América: autorreflexiones y propuestas" Pensamiento anticolonial de nuestra América. Buenos Aires: CLACSO, 2016. 347-374.

Grüner, Eduardo. “Ausencias posibles, presencias imposibles. 'Africanía' y complejidad transcultural en Fernando Ortiz, Gilberto Freyre y Roberto Fernández Retamar (primera parte)". Nuestra América y el pensar crítico: fragmentos del pensamiento crítico de Latinoamérica y el Caribe. Eduardo Grüner - coordinador. Buenos Aires: CLACSO, 2011. 265-308.

Hall, Stuart. "Antiguas y nuevas identidades y etnicidades". Sin garantías: Trayectorias y problemáticas en estudios culturales. Eduardo Restrepo, 
Catherine Walsh y Víctor Vich - editores. Popayán: Envión editores, 2010.315-336.

. ¿Cuando fue lo poscolonial? Pensar el límite”, Estudios Poscoloniales. Ensayos fundamentales. Madrid: Traficantes de sueños, 2008. 121-144. . ¿Cuándo fue lo “postcolonial”? Pensando en el límite. Sin garantías: Trayectorias y problemáticas en estudios culturales. Eduardo Restrepo, Catherine Walsh y Víctor Vich - editores. Popayán: Envión editores, 2010. 563-582.

Quijano, Aníbal. "Colonialidad del poder y clasificación social”. El giro decolonial: reflexiones para una diversidad epistémica más allá del capitalismo global. Santiago Castro-Gómez y Ramón Grosfoguel editores. Bogotá: Siglo del Hombre Editores, 2007. 93-126.

Mbembe, Achille. Crítica de la razón negra. Buenos Aires: Futuro Anterior Ediciones, 2016.

Mignolo, Walter. Historias locales/diseños globales. Colonialidad, conocimientos subalternos y pensamiento fronterizo. Madrid: Akal, 2013.

. "Occidentalización, imperialismo, globalización: herencias coloniales y teorías poscoloniales”, Revista Iberoamericana, 61/170-171 (1995): 2740.

. "Posoccidentalismo: las epistemologías de fronterizas y el dilema de los estudios (latinoamericanos) de área", Revista Iberoamericana, 68/200 (2002): 856-862.

Trouillot, Michel-Rolph. Silenciando el pasado: El poder y la producción de la Historia. Granada: Editorial Comares, 2017.

Said, Edward. El mundo, el texto y el crítico. Buenos Aires: Debate, 2004. Santiago, Silviano. "El entre-lugar del discurso latinoamericano". Una literatura en los trópicos. Ensayos escogidos. Adrogué: Ediciones La Cebra, 2018. 61-82. 
Viala, Fabienne. "Tragedia, filosofía y cultura para Alejo Carpentier y Aimé Césaire. Haití como paradigma histórico caribeño". Anales del Caribe (2016): 292-303. 